\title{
Radiographic Employment of Mandibular Third-Molar Mineralisation to Estimate Chronological Age in a Population of Peshawar, Pakistan
}

\author{
Quratulain Tariq ${ }^{1} \quad$ BDS \\ Mariam Ajmal Tareen ${ }^{2} \quad$ BDS \\ Iftikhar Uddin ${ }^{3} \quad$ PhD \\ Umar Hussain ${ }^{4} \quad$ BDS
}

OBJECTIVES: To determine the correlation between chronological age (CA) and mandibular third molar (MTM) development in a sample of Khyber Pakhtunkhwa (KP) population. Furthermore, to provide forensic reference data for age determination from MTM mineralisation. Finally, to derive regression formulae specific to this population to estimate age using MTM calcification stages.

METHODOLOGY: Four hundred and seventy orthopantomographs (OPGs) of patients aged between 13-26 years from the Orthodontics department archive at the main tertiary dental hospital of KP were studied for development of MTM staging using Demirjian's method. Spearman's Correlation was applied to determine any relationship between CA and MTM development. An Independent two-sample t-test was performed to compare third-molar development in males and females. Population-specific models was developed using quantile regression analysis.

RESULTS: A strong positive correlation was found between CA and MTM development ( $\mathrm{rs}=0.853$; $\mathrm{p}-<0.001$ ). The median quantile regression equation developed for entire sample is: Age $=8.8+1.4$ (developmental stage). Ninety-four percent of males and females at stage $\mathrm{H}$ were at least 18 years or older.

CONCLUSION: Mandibular third-molars can be an appropriate guide for CA estimation in the KP population. Stage H is likely to occur at 18 years of age. This may be valuable for medicolegal suits requiring CA estimation.

KEYWORDS: forensic odontology, forensic anthropology, panoramic radiographs, chronological age estimation, mandibular third-molar, Pakistan

HOW TO CITE: Tariq Q, Tareen MA, Uddin I, Hussain U. Radiographic employment of mandibular third-molar mineralisation to estimate chronological age in a population of Peshawar, Pakistan. J Pak Dent Assoc 2021;30(1):39-44.

DOI: https://doi.org/10.25301/JPDA.301.39

Received: 15 July 2020, Accepted: 11 November 2020

\section{INTRODUCTION}

$\mathrm{R}$ adiographic studies of skeletal and dental development have been preferentially adopted as a non-invasive method for the estimation of chronological age for both the dead and living individuals. It avoids the need for dental extraction or histological preparation of tissue. ${ }^{1}$ Dental age has persistently corresponded to specific ranges of CA, for example, the

1. Foundation Dentist (House Officer), Department of Out-patient department, Khyber College of Dentistry, Peshawar.

2. Foundation Dentist (House Officer), Department of Out-patient department, Khyber College of Dentistry, Peshawar.

3. Assistant Professor, Department of Mathematics and Biostatistics, University of Agriculture Peshawar.

4. FCPS II trainee, Department of Orthodontics, KhyberCollege of Dentistry.

Corresponding author: “Dr. Quratulain Tariq” < qtariq03@gmail.com > eruption of permanent first molars is generally expected by 6-7 years of age. However, the accuracy with which age can be correlated with dentition stages is limited to the eruption of second-molars. After which, third-molars are the only teeth developing and radiographically employable for age estimation during adolescence and early adulthood..$^{2,3,4}$

Crypts of third-molars can be depicted radiographically on average as early as 8 years after birth. ${ }^{5}$ In a longitudinal study, Garn et $\mathrm{al}^{6}$ showed that third-molar development continues a further 12 years of age until the closure of root apices. Undoubtedly this lengthy period increases risk of inconsistency in its development. Third molars are known to be the most variant tooth and have the highest rate agenesis. ${ }^{6}$ Nonetheless, several studies have shown great interest in utilising third-molar for chronological age estimation focusing on its mineralisation stages. ${ }^{3,7}$ Several classifications of tooth 
development stages have been developed in this regard of which Demirjian's [ANNEXURE 1] is considered the most efficacious and is extensively used because of greater observer agreement. ${ }^{7,8}$ Demirjian et al developed a maturity scoring system to determine dental age in children for universal use but it is not applicable to some populations including that of Pakistani children. ${ }^{9-12}$ The present study, however, does not use their proposed method rather it only utilises their developmental stages of the MTM.

Previous studies have shown a positive correlation between chronological age and third-molar developmental stages and have formulated population-specific regression models for age calculation. The objectives of our study were to determine a correlation between CA and MTM development in a population of KP, north western province of Pakistan, to provide forensic reference data of CA at critical dental developmental landmarks and to develop a model specific to this populace.

\section{METHODOLOGY}

This retrospective cross-sectional analytical study was conducted at the Department of Orthodontics, Khyber College of Dentistry (KCD), Khyber Pakhtunkhwa. Panoramic radiographs of 470 orthodontic patients pertaining to the years: Jan 2016 to May 2018, were studied. The sample size was calculated using Yamane's formula:

$\mathrm{n}=\mathrm{N} /\left(1+\mathrm{N}(\mathrm{e})^{2}\right)$. For projected population of KP between 13 to 26 years, $\mathrm{N}=8468438$ and a margin of error $\mathrm{e}=0.046$ the estimated sample size $\mathrm{n}=8468438 /$ $\left(1+8468438(0.046)^{2}\right), \mathrm{n}=470$ approx. Subjects who were natives of KP visiting orthodontics department at KCD and aged between 13-26 years were included. The following were excluded: any skeletal or dental pathology (impactions, anomalies, agenesis, transpositions, skeletal class II or III jaw profile, cleft lip and palate etc), any systemic developmental disturbances, previous surgery affecting the jaw or dental development and any radiographic artefacts affecting MTM region.

To carry out the study, approval was taken from the Institutional Ethical Review Committee at KCD. Data was collected by studying the developmental stages of MTMs from OPGs of both males and females aged between 13 to 26 years. Age was calculated from the date of birth stated in the patients' files to the date on which the OPG was taken. For the developmental stage assessment Demirjian's et al ${ }^{7}$ classification system was utilised which states 8 developmental stages (A-H). Stage 0 was applied for the presence of merely a tooth crypt. All OPGs were assessed under radiographic illuminator by two observers.

The collected data were analysed using Statistical Package for Social Sciences (SPSS) version 22. Inter-observer agreement was assessed using Cohen's kappa statistics. Descriptive statistics like frequency, mean, standard deviation and percentage distribution of chronological ages for the eight Demirjian stages were calculated. Spearman's correlation was used to determine if correlation exists between CA and Demirjian developmental stages of MTM. An Independent two-sample t-test was applied to examine the statistical significance of the variations observed in the ages of males and females at each stage. Quantile regression analysis was carried out using Software for Statistics and Data Science (STATA) version 12 to develop equations to estimate chronological age for the entire sample and for males and females separately.

\section{RESULTS}

There was an almost perfect degree of agreement with Kappa value of 0.815 between the 2 observers for $n=470$ cases $(\mathrm{p}<0.0001)$.

There were $215(45.7 \%)$ males with an average age of $17.2 \pm 3.7$ years and $255(54.3 \%)$ females with an average age of $17.6 \pm 3.7$ years. The frequency of each Demirjian stage and mean age at each stage for both males and females is given in table 1 .

Results from our study sample show a strong positive linear trend between CA and Demirjians development stages of both 38 and 48 (see Fig.1). Spearman rank-order correlation coefficient $\left(\mathrm{r}_{\mathrm{s}}\right)$ indicated a strong positive association between CA and developmental stages of teeth $38\left(r_{s}=0.840\right)$ and $48\left(\mathrm{r}_{\mathrm{s}}=0.853\right)$, which is highly statistically significant $(\mathrm{p}<0.0001)$. Males showed slightly greater correlation between CA and development of both 38 (males $r_{s}=0.845$; females $r_{s}=0.832$ ) and 48 (males $r_{s}=0.862$; females $r_{s}=0.840$ ).

Figure 1: Mean plots for each developmental stage of 38 and 48 .

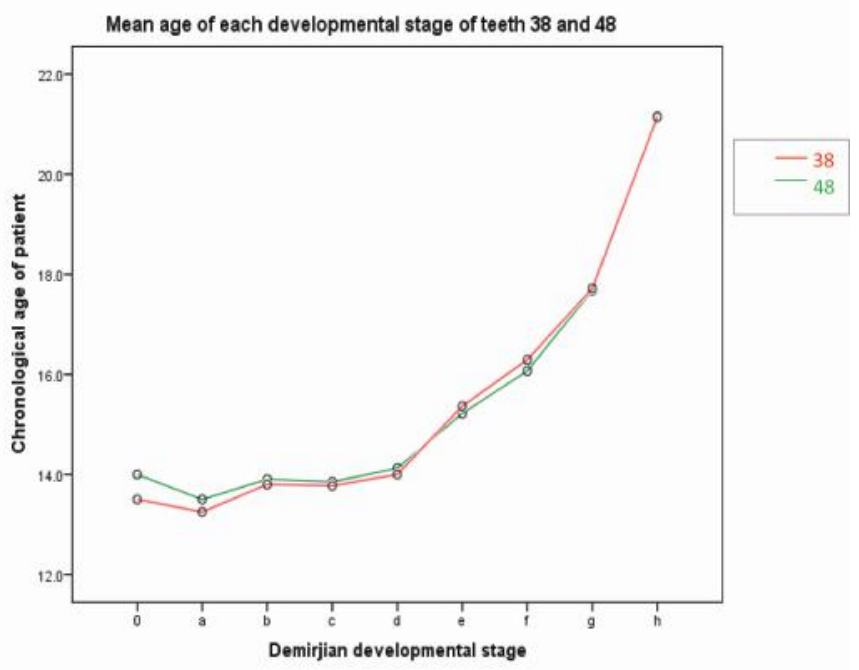


Table 1:Mean ages of males and females at various Demirjian's stages of teeth 38 and 48.

\begin{tabular}{|c|c|c|c|c|c|c|c|c|c|c|c|}
\hline \multicolumn{7}{|c|}{ Chronological ages corresponding to 38} & \multicolumn{5}{|c|}{ Chronological ages corresponding to 48} \\
\hline $\begin{array}{l}\text { Demirjin } \\
\text { n stage }\end{array}$ & Gender & Mean & $\mathbf{N}$ & SD & Min & $\operatorname{Max}$ & Mean & $\mathbf{N}$ & SD & Min & Max \\
\hline 0 & \begin{tabular}{|l|} 
Mule \\
Female
\end{tabular} & 14.60 & 1.00 & & 14.00 & 14.00 & $\begin{array}{l}13.00 \\
14.00\end{array}$ & $\begin{array}{l}1.00 \\
1.00\end{array}$ & & $\begin{array}{l}13.00 \\
14.00\end{array}$ & $\begin{array}{l}13.00 \\
14.90\end{array}$ \\
\hline A & \begin{tabular}{|l} 
Mule \\
Female
\end{tabular} & $\begin{array}{l}13.00 \\
14.00\end{array}$ & $\begin{array}{l}1.00 \\
1.00\end{array}$ & & $\begin{array}{l}13.010 \\
14.00\end{array}$ & $\begin{array}{l}13.00 \\
14.00\end{array}$ & $\begin{array}{l}13.33 \\
13.00\end{array}$ & $\begin{array}{l}3.000 \\
1.00\end{array}$ & 0.57 & $\begin{array}{l}13.100 \\
13.00\end{array}$ & $\begin{array}{l}14.60 \\
13.00\end{array}$ \\
\hline \multirow[t]{2}{*}{ B } & Male & 14.25 & 12.80 & 1.65 & $13 . .10$ & 19.00 & 14.90 & 9.80 & e.7n & 13.180 & 15.ae \\
\hline & Female & 13.44 & 9.00 & 0.52 & 13.00 & 14.00 & 13.50 & 6.00 & 0.83 & 13.00 & 15.00 \\
\hline \multirow[t]{2}{*}{ c } & Male & 13.62 & 24.00 & 0.92 & 13.40 & 17.00 & 13.74 & 27.00 & 6.94 & 13.00 & 17.90 \\
\hline & Female & 14.08 & 23.00 & 1.56 & 13.00 & 19.00 & 1380 & 26.00 & 1.99 & 13.00 & 17.00 \\
\hline \multirow[t]{2}{*}{ D } & Male & 14.28 & 32.00 & 1.27 & 13.00 & 18.00 & 14.06 & 38.00 & 1.17 & 13.00 & 17.60 \\
\hline & Female & 14.00 & 38.00 & 1.39 & 13.00 & 18.00 & 1394 & 36.00 & 1.41 & 13.00 & 19.00 \\
\hline \multirow[t]{2}{*}{ E } & Male & 14.79 & 24.90 & 1.28 & 13.00 & 17.00 & 15.03 & 26.00 & 1.37 & 13.00 & 18.60 \\
\hline & Female & 15.51 & 35.00 & 2.42 & 13.00 & 26.00 & 15.59 & 37.00 & 2.39 & 13.00 & 26.00 \\
\hline \multirow[t]{2}{*}{ F } & Male & 15.81 & 22.00 & 1.91 & 13.00 & 21.00 & 16.90 & 22.00 & 2.02 & 13.100 & 21.90 \\
\hline & Female & 16.35 & 20.00 & 1.98 & 14.00 & 21.00 & 16.63 & 19.00 & 1.92 & 14.00 & 21.00 \\
\hline \multirow[t]{2}{*}{ G } & Male & 17.27 & 18.00 & 2.53 & 13.160 & 25,00 & 17.40 & 15.00 & 2.44 & 14.00 & 25.00 \\
\hline & Female & 17.93 & 29.00 & 2.18 & 14.00 & 24.00 & 17.89 & 28.00 & 2.24 & 14.00 & 24.00 \\
\hline \multirow[t]{2}{*}{ н } & Male & 21.22 & 81.90 & 2.33 & 16.00 & 25.00 & 21.20 & 82.00 & 2.32 & 16.00 & 25.90 \\
\hline & Female & 21.13 & 100.00 & 2.54 & 16.00 & 26.00 & 21.09 & 101.00 & 2.53 & 16.00 & 26.00 \\
\hline
\end{tabular}

Further analysis was performed with data of 48 as it exhibited greater correlation with CA for both sexes than 38 .

Independent samples t-test showed no statistically significant differences between mean ages of males and females in any developmental stage for tooth 48 . There were a negligible few individuals in whom MTM crypts were observed as late as 13 to 14 years of age. Stage A was observed on average within the 13th year. Between stages B-D, age remained relatively constant (see Fig.1). Stage D (crown completion) was predominantly observed around 14 years of age for both sexes (see Fig.2). Eighty-eight percent of females and $86 \%$ of males were at least 14 years of age at stage D (see Fig.3). Dental maturation from stage D to E occurred over a period of 1.5 years for females and 1 year for males (see Table 1). After which both males and females

Figure 2: Mean ages of males and females plotted against developmental stages

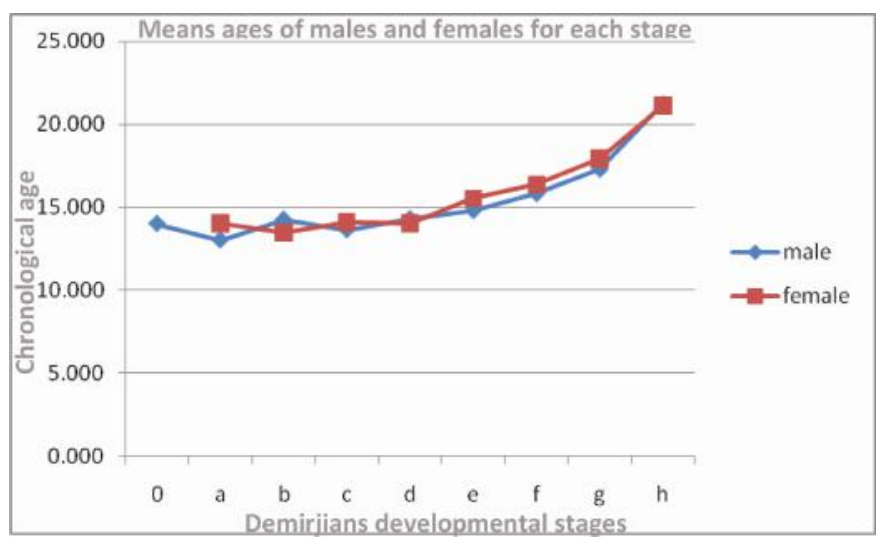

attained stages $F$ and $G$ at a similar period (see Fig. 2). Stage G (root-length completion) was predominantly observed after 17 years of age in both males and females. Seventy-one percent of females at stage $\mathrm{G}$ were $>17$ years and $67 \%$ of males at stage $\mathrm{G}$ were $>17$ years of age (see Fig.4). Stage H (apical closure) was obtained at 16 years of age at the earliest in both males and females. At stage $\mathrm{H}$, $94 \%$ of males and $95 \%$ of females were $>18$ years (see Fig. $5)$.

Through quantile regression analysis, statistical models were developed by which chronological age can be estimated using Demirjian's developmental stages ( $\mathrm{p}<0.0001)$ :

Figure 3: Percentage of males and females in certain ages within stage D (crown completion)

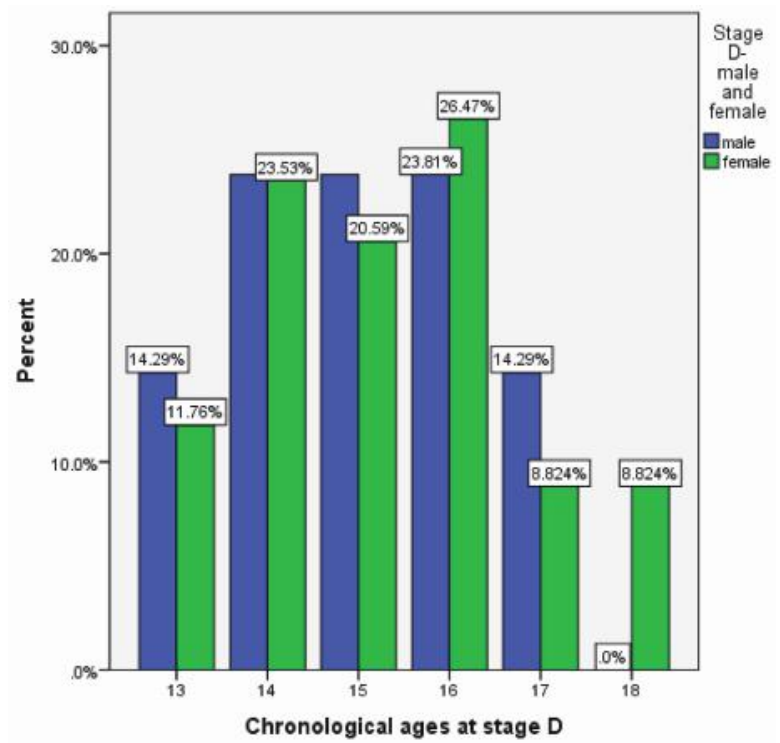

Figure 4: Percentage of males and females at certain ages within stage $\mathrm{G}$ (root length completion)

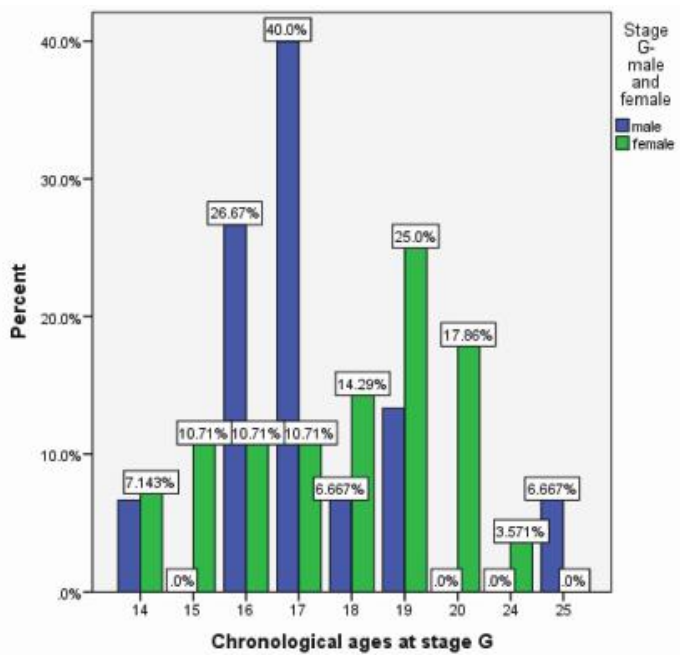


Figure 5: Percentage of males and females at certain ages within stage $\mathrm{H}$ (tooth formation complete)

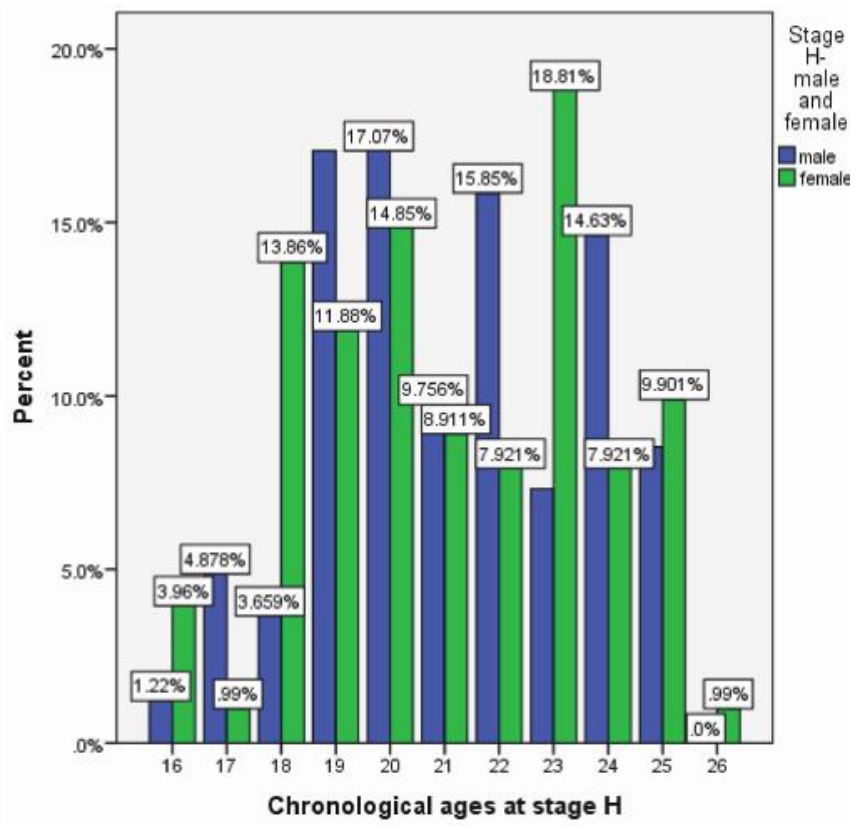

Entire sample:

Quantile Regression at median(17) Age $=8.8+1.4$ (developmental stage), pseudo $\mathrm{R}^{2}=0.45$

0.25 (14) Quantile Age $=10+1.0($ developmental stage $)$, pseudo $\mathrm{R}^{2}=0.37$

0.75 (20) Quantile Age $=10+1.5($ developmental stage $)$, pseudo $\mathrm{R}^{2}=0.43$

\section{For Males:}

At median(16) Age $=8.8+1.4$ (developmental stage), pseudo $\mathrm{R}^{2}=0.45$

0.25 (14) Quantile Age $=10+1.0$ (developmental stage), pseudo $\mathrm{R}^{2}=0.37$

0.75(20) Quantile Age $=10+1.5$ (developmental stage), pseudo $\mathrm{R}^{2}=0.45$

\section{For Females:}

At Median(17) Age $=8.8+1.4$ (developmental stage), pseudo $\mathrm{R}^{2}=0.45$

0.25 (14) Quantile Age = 7. 7+ 1.3 (developmental stage), pseudo $\mathrm{R}^{2}=0.38$

0.75 (20) Quantile Age $=8.6+1.8$ (developmental stage), pseudo $\mathrm{R}^{2}=0.41$

McFadden's pseudo $\mathrm{R}^{2}$ indicates goodness of fit of the aforementioned models. The larger pseudo $\mathrm{R}^{2}$ values indicate which model better predicts the outcome. When interested in predicting around the median age value ${ }^{17}$ then Quantile regression median is appropriate. Similarly, when estimating around the 0.25 th quantile i.e. age value ${ }^{14}$ or around the
0.75 th quantile, i.e. age value ${ }^{20}$, the Quantile regression median is also appropriate.

\section{DISCUSSION}

The results from our study show a strong positive correlation exists between MTM development and chronological age in a KP population. This is a similar finding to studies conducted on Central European ${ }^{13}$, Indian ${ }^{14}$, Iranian ${ }^{15}$, Chinese ${ }^{16}$, Japanese, South African ${ }^{17}$, Turkish ${ }^{18}$, Aboriginal-Canadians ${ }^{19}$, American ${ }^{3}$ and Brazilian ${ }^{20}$ populations.

According to Mincer, et $\mathrm{al}^{2}$ sexual dimorphism influences mineralisation of MTM: males being more advanced in development than females. Studies conducted on Turkish[18] Indians ${ }^{21}$ and Swedish ${ }^{22}$ citizens support this. However it was observed that in Iranian females were significantly younger than their male counterparts at stage $\mathrm{H} .{ }^{23}$ Contrary to this, there were no statistically significant differences between males and females in our study and that of a population in Brazil. ${ }^{20}$

Eighty-six percent of males and $88 \%$ of females of our population were at least 14 years of age at stage $\mathrm{D}$ (crown completion). This is comparable to the Turkish ${ }^{18}$, Chinese $^{16}$, South African ${ }^{17}$ and Iranian ${ }^{15}$ populations (stage D was obtained on average at 14 years of age) and also close to Swedish $^{22}$, American (Caucasian, Hispanic and African) populations ${ }^{3}$ in whom crown completion was attained by 15 years of age. Whereas the German, Indian and Japanese populations were much older at stage $\mathrm{D}$ : a mean age of 16 years, 17 years and 18 years respectively. ${ }^{14,17}$

In the present work, stage G, illustrative of root-length completion, was observed at 17 years of age with $67 \%$ of males and $71 \%$ of females being 17 years and older. A recent study on a Han population in China ${ }^{16}$ concluded that it was likely for a citizen to be over 14 at stage G. The Turkish ${ }^{18}$, Swedish $^{22}$ and American (Caucasian, African and Hispanic) citizens $^{3}$ were 18 years of age upon reaching stage $\mathrm{G}$. Whereas the German, Japanese and South African populations reached this stage even later: at the age of twenty-one. ${ }^{17}$

Lui $\mathrm{Y}$, et $\mathrm{al}^{16}$ found that stage $\mathrm{H}$ was obtained at a minimum age of 16 years in a population of Southern China. The present study reports an identical finding. The likelihood of males and females of KP province being 18 years and older at stage $\mathrm{H}$ is $94 \%$ and $95 \%$ respectively. This is alike to Belgian Caucasian males (96\%) and females (95\%) and of American (Caucasians and African) citizens (90\%) and Hispanics $(85 \%)$ were 18 years old upon attaining stage H. ${ }^{3,24}$ Similarly stage $\mathrm{H}$ was attained by 18 years of age in a Brazilian population. ${ }^{20}$ On the other hand the Japanese, German, and South African populations were all at an average 
age of 22 years. ${ }^{17}$ It was concluded that MTM formation may complete after 22 years of age among Iranians. ${ }^{23} \mathrm{~A}$ study on the Indian population concluded that $90 \%$ of males will reach stage $\mathrm{H}$ by 21 years and females by 23 years. ${ }^{21}$ Though the study sample reached crown completion stage and root-length completion stage earlier than the other ethnicities, at stage $\mathrm{H}$ the percentage of individuals being 18 or older was the same (>90\%) for them and for Belgian Caucasian, American White and Black, and Spanish populations. Similarly there were significant differences between the Caucasian Americans and African Americans and between the German, Japanese and South African populations in the earlier stages (D-G) of development but all reached stage $\mathrm{H}$ at ages that were at par with each other in the respective studies. ${ }^{3,17}$ The variations in CA at earlier stages diminished towards the completion of MTM formation amongst some populations.

Although currently there is no study that has utilised quantile regression to develop statistical models for CA estimation from mineralisation stages of MTM, Khan et al found quantile regression was more accurate than linear regression in estimating dental age of Pakistani children whereas Iftikhar et al developed growth charts specifically for Pakistani children using quantile regression which were more accurate than the anthropometric data proposed by World Health Organisation..$^{21,22}$

There are potential limitations to this study. The present work is a single hospital-based study which may not be as representative of the general population opposed to a larger sample-based study taken from various centres of the province. Random selection of sample was limited as only those radiographs available in the archive were studied. However additional exposure for this purpose was unjustified. Follow-up radiographs of study subjects would give a greater accuracy of correlation of CA and tooth developmental stage than a retrospective study.

\section{CONCLUSION}

Developmental stages of MTM can be used as an indicator for age for Pashtun population of Pakistan. Males and females of this population do not have statistically significant variations. It is highly likely that males and females of this populace will be at least 18 years at stage $\mathrm{H}$. This can be of great value in medicolegal lawsuits requiring age estimation.

\section{RECOMMENDATIONS}

Though the regression formulae closely fit the observed data, additional prediction tests may be applied for further verification of the goodness of fit of these regression models. Studies with larger samples sizes and different tribes residing at KP should be conducted to provide additional data for forensic use.

\section{CONFLICTS OF INTEREST STATEMENT}

The authors declare no conflicts of interest in this submission

\section{REFERENCES}

1. Panchbhai AS. Dental radiographic indicators, a key to age estimation. Dentomaxillofac Radiolog, 2011; 40:199-212

https://doi.org/10.1259/dmfr/19478385

2.Mincer HH, Harris EF, Berryman HE. The A.B.F.O. study of third molar development and its use as an estimator of chronological age. J Forensic Sci, 1993; 38:379-90.

https://doi.org/10.1520/JFS13418J

3.Lewis JM, Senn DR. Dental age estimation utilizing third molar development: A review of principles, methods, and population studies used in the United States. ForensicSci Int, 2010; 201:79-83. https://doi.org/10.1016/j.forsciint.2010.04.042

4. Zandi M, Shokri A, Malekzadeh H, Amini P, Shafiey P. Evaluation of third molar development and its relation to chronological age: a panoramic radiographic study. Oral Maxillofac Surg, 2015; 19:183. https://doi.org/10.1007/s10006-014-0475-0

5.Bishara SE, Andreasen SG. Third molars: a review. Am J Orthod, $1983 ; 83: 131-37$

https://doi.org/10.1016/S0002-9416(83)90298-1

6.Garn SN, Lewis AB, Bonne B. Third molar formation and its developmental course. Angle Orthod, 1962; 32:270-79.

7. Olze A, Bilang D, Schmidt S, Wernecke KD, Geserick G, Schmeling A. Validation of common classification systems for assessing the mineralization of third molars. Int J Legal Med, 2005; 119:22-26. https://doi.org/10.1007/s00414-004-0489-5

8. Demirjian A, Goldstein H, Tanner JM. A new system of dental age assessment. Ann Hum Biol, 1973; 45:211-27.

9. Ali AM, Ahmed WH, Khattab NM. Applicability of Demirjian's method for dental age estimation in a group of Egyptian children. Brit Dent J, 2019;5:1-6.

https://doi.org/10.1038/s41405-019-0015-y

10. Alqadi MA, Abuaffan AH. Validity of the Demirjian and Fishman Methods for Predicting Chronological Age Amongst Yemeni Children. Sultan Qaboos Uni Med J. 2019;19:e26. https://doi.org/10.18295/squmj.2019.19.01.006

11. Sukhia RH, Fida M, Azam SI. Dental age table for a sample of Pakistani children. Eur J Orthodo, 2012; 34:77-82.

https://doi.org/10.1093/ejo/cjq161 
12. Esan TA, Yengopal V, Schepartz LA. The Demirjian versus the Willems method for dental age estimation in different populations: A meta-analysis of published studies. PloS one, 2017; 12:e0186682. https://doi.org/10.1371/journal.pone.0186682

13. Hofmann E, Robold M, Proff P, Krischneck C. Age assessment based on third molar mineralisation. J Orofac Orthop, 2017; 78:97111.

https://doi.org/10.1007/s00056-016-0063-z

14.Priyadharshini K I, Idiculla JJ, Sivapathasundaram B, Mohanbabu V, Augustine D, Patil S. Age estimation using development of third molars in South Indian population: A radiological study. J Int Soc Prevent Communit Dent. 2015;5:32-8 https://doi.org/10.4103/2231-0762.156522

15. Monirifard M, Yaraghi N, Vali A, Vali A, Vali A. Radiographic assessment of third molars development and it's relation to dental and chronological age in an Iranian population. Dent Res J. 2015;12:6470.

https://doi.org/10.4103/1735-3327.150334

16. Liu Y, Geng K, Chu Y, Xu M, Zha L. Third molar mineralization in relation to chronologic age estimation of the Han in central southern China. Int J Legal Med, 2018;132:1427.

https://doi.org/10.1007/s00414-018-1804-x

17.Olze A, Schmeling A, Taniguchi M, Maeda H, Van Niekerk P, Wernecke KD, et al. Forensic age estimation in living subjects: the ethnic factor in wisdom teeth mineralization. Int J Leg Med, 2004; 118:170-173.

https://doi.org/10.1007/s00414-004-0434-7

18. Orhan K, Ozer L, Orhan AI, Dogan S, Paksoy CS. Radiographic evaluation of third-molar development in relation to chronological age among Turkish children and youth. Forensic Sci Int, 2007;165:4651 .

https://doi.org/10.1016/j.forsciint.2006.02.046

19. Olze A, Pynn BR, Kraul V, Schulz R, Heinecke A, Pfeiffer H, et al. Studies on the chronology of third molar mineralization in First Nations people of Canada. Int J Legal Med, 2010; 124:433-37. https://doi.org/10.1007/s00414-010-0483-z
20. Soares CBRB, Figueiroa JN, Dantas RMX, Kurita LM, Pontual AA, Ramos-Perez FMM, et al. Evaluation of third molar development in the estimation of chronological age. Forensic Sci Int, 2015; 254:13-17. https://doi.org/10.1016/j.forsciint.2015.06.022

21. Babburi S, Nelakurthi H, Aparna V, Soujanya P, Kotti AB, Ganipineni K. Radiographic estimation of chronological age using mineralization of third molars in coastal Andhra, India. J Int Oral Health, 2015; 7:49-52.

22. Simonsson L, Näsström Ka, Kullman L. Radiographic evaluation of third mandibular molar development as an age indicator in a Swedish population. Madridge J Dent Oral Surg. 2017; 2:31-7.

https://doi.org/10.18689/mjdl-1000108

23. Khosronejad A, Navabi M, Sakhdari S, Rakhshan V. Correlation between chronological age and third molar developmental stages in an Iranian population (Demirjian method). Dent Res J. 2017;14: 143-49.

24. Gunst K, Mesotten K, Carbonez A, Willems G. Third molar root development in relation to chronological age: a large sample sized retrospective study. Forensic Sci Int, 2003;136:52-7.

https://doi.org/10.1016/S0379-0738(03)00263-9

25. Prieto JL, Barberia E, Ortega R, Magana C. Evaluation of chronological age based on third molar development in the Spanish population. Int J Legal Med, 2005; 119:349-54

https://doi.org/10.1007/s00414-005-0530-3

26. Sisman Y, Uysal T, Yagmur F, Ramoglu SI. Third-molar development in relation to chronologic age in Turkish children and young adults. Angle Orthodontist, 2007; 77:1040-45 https://doi.org/10.2319/101906-430.1

27.Khan NB, Iftikhar S. Age Estimation of School Going Children of Pakistan by Number of Erupted Teeth Using Median Regression. Ann Jinnah Sindh Med Uni. 2015; 1:3-5

28. Iftikhar S, Khan N, Siddiqui JS, Baig NA. Development of growth charts of Pakistani children using quantile regression. Cureas, 2018; 10:e2138.

https://doi.org/10.7759/cureus. 2138 